\title{
Ionospheric transients observed at mid-latitudes prior to earthquake activity in Central Italy
}

\author{
P. Nenovski ${ }^{1}$, Ch. Spassov ${ }^{1}$, M. Pezzopane ${ }^{2}$, U. Villante ${ }^{3,4}$, M. Vellante ${ }^{3,4}$, and M. Serafimova ${ }^{1}$ \\ ${ }^{1}$ Geophysical Institute, Bulgarian Academy of Sciences, 1113 Sofia, Bulgaria \\ ${ }^{2}$ Istituto Nazionale di Geofisica e Vulcanologia, Rome, Italy \\ ${ }^{3}$ Dipartimento di Fisica, Università dell'Aquila, L'Aquila, Italy \\ ${ }^{4}$ Consorzio Area di Ricerca in Astrogeofisica, L'Aquila, Italy
}

Received: 6 November 2009 - Revised: 17 May 2010 - Accepted: 17 May 2010 - Published: 17 June 2010

\begin{abstract}
Ionograms from Rome (41.8N, 12.5E) and Sofia (42.4N, 23.2E) ionospheric stations during earthquake (EQ) activity with magnitude $(M)$ between 5 and 6 in Central Italy are analyzed. It is found that several ionospheric disturbances occur in the intermediate E-F region before the EQ shock. In fact, besides sporadic E (Es) layer development (of type h) of short duration (transients), fmin increase, trace gaps near the critical frequencies, and E region trace disappearance are also observed within one to three hours before the EQ shock. Before the EQ shocks we find that the F2 region parameters are practically undisturbed. The only exception is the so-called fork trace that appears mostly near the critical frequency of the F2 region. Acoustic gravity waves (AGW) are suggested as one of the possible sources of transients observed in the ionosphere before the EQ shock.
\end{abstract}

\section{Introduction and physical background}

The interaction of powerful processes, which take place in the Earth crust, e.g. earthquakes (EQs), volcanoes, etc., with neutral and charged components of the atmosphere (ionosphere) is one of the most important problems of our environment. Evidences for ionospheric disturbances emerging days before the strong EQ shocks are widely considered in the literature. Data from a number of vertical sounding ionosondes have been analyzed for a thorough study of the F2 region ionosphere behavior. Ionospheric disturbances in the F2 region have been shown to appear generally 1-7 days before the EQ event (Pulinets and Boyarchuk, 2004; Hayakawa, 1999 and references therein; Hayakawa and Molchanov, 2002 and references therein). At heights

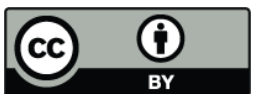

Correspondence to: P. Nenovski (pnenovski@geophys.bas.bg) of the maximum of the $\mathrm{F} 2$ region, the corresponding critical frequency (foF2) is strongly influenced by EQ preparation processes. Then the variations from its median values can exceed twice the standard deviation. Moreover, their localization is found to be centered at, or near the epicenter of the forthcoming EQ (Liu et al., 2001, 2006). Analysis of GPS total electron content (TEC) data within the area affected by the EQ has revealed a systematic ionospheric variability several days before the seismic shock as shown for instance by Liu et al. $(2004,2006)$ who observed a TEC variation up to 40 TEC units. It is worth noting that for the same set of GPS receivers this type of variability does not appear during geomagnetically disturbed periods.

Disturbances affecting the E and D ionospheric regions days before strong EQs have also been observed. First experimental evidences concerning the $\mathrm{D}$ region disturbances during the EQ preparation period are changes of the characteristics of VLF signals received by ground-based receivers from remote transmitters (Gokhberg et al., 1987, 1989). As for EQ-related disturbances in the $\mathrm{E}$ region there is a row of cases and statistical studies. The most frequent feature characterizing the $\mathrm{E}$ region is the appearance several days before of strong Es layers over the zone affected by the EQ (Ondoh and Hayakawa, 1999; Liperovsky et al., 2000; Pulinets et al., 2000; Chuo et al., 2002). The number of spread-Es observations is reported to increase one to three days before an EQ (Silina et al., 2001). The spread-Es phenomenon appears as diffusivity of the traces of Es layers on the ionograms of vertical sounding stations (Liperovsky et al., 2005). The importance of Es layer formation and its modification during EQ preparation processes is underlined by statistical studies performed on the available data (Liperovsky et al., 2000). Recently, Ondoh (2003) has registered an emergence of strong increase of the critical frequency of the Es layer, foEs, (up to above $7 \mathrm{MHz}$ ) two days before the Hyogo-ken Nanbu (Kobe) EQ $(M=7.2)$ on 17 January 1995. Chuo et

Published by Copernicus Publications on behalf of the European Geosciences Union. 
al. (2002) have conducted statistical studies of the foEs variations before Taiwan EQs with $M$ higher than 6. Most sharp variations of foEs thus have been observed during terminator time (sunrise and sunset at E region heights) within the interval of 5 days before the seismic shock. Increases of the Es layer critical frequency at terminator time give rise to an electron concentration increase in the $\mathrm{D}$ region; the effect of terminator time variations in VLF propagation signals observed by many groups (Gokhberg e al., 1987; Molchanov and Hayakawa, 1998, Biagi et al., 2001) and foEs variations are then closely interrelated.

In order to characterize the presence of small-scale plasma turbulence for thin layers, variations of the Es region semi transparency coefficient $X=$ (foEs - fbEs)/fbEs (where $\mathrm{fbEs}$ is the blanketing frequency of the Es layer) have been analyzed for more than $100 \mathrm{EQs}$ with $M>4$ and depth $h<100 \mathrm{~km}$ (Liperovskaya et al., 2003). Liperovskaya et al. (2003) have shown that the turbulence level decreases by $\sim 10 \%$ during three days before EQs. The turbulence level however increases by the same value from one to three days after the shocks. For EQs with $M>5$ the effect exists at distances up to $300 \mathrm{~km}$ from the epicenter. The effect could also exist for weak $(M \sim 4)$ and shallow (depth $<50 \mathrm{~km})$ EQs at a distance smaller than $200 \mathrm{~km}$ from the epicenter (Liperovskaya et al., 2003). One may expect that $\mathrm{E}$ region plasma density variations as high as $5-10 \%$ will result in corresponding variations of the ionospheric current intensity as the Sqsystem, as well. Having in mind that the ionospheric current densities are of order of $10^{-6} \mathrm{~A} / \mathrm{m}^{2}$ (Onwumechili, 1992), the velocity of the current carrier should be of the order of several $100 \mathrm{~m} / \mathrm{s}$. Hence, small-scale plasma density disturbances of about 10-100 km would result in time scale of 100 up to $1000 \mathrm{~s}$. Associated ULF variations (up to $5 \%$ ) in the current density in the $\mathrm{E}$ region heights and in the geomagnetic field on the ground (prior or after the EQ shocks) can be also expected.

It is worth noting that among all ionospheric disturbances and anomalies that appear usually 7-2 days or hours before strong EQs, only ionospheric disturbances starting hours before the EQ shocks seem to be related (at least in time) to the intensity bursts of EQ-related geomagnetic field variations. An exceptionally high level of activity in the 10$500 \mathrm{mHz}$ range starting three hours before the Loma-Pietra EQ $(M=7.1)$ has been observed by Fraser-Smith et al. (1990). Again, an increased ULF activity started growing three to five days before the Spitak EQ $(M=6.9)$ was seen to be accompanied by a substantial ULF emission burst starting four hours before the EQ shock (Molchanov et al., 1992). These activities have been identified respectively at distances of $7 \mathrm{~km}$ (Loma-Prieta EQ) and of $130 \mathrm{~km}$ (Spitak EQ) from the EQ epicenters.

The first who has observed and identified ionospheric disturbances hours before strong EQ, as well as their propagation characteristics is Nestorov $(1979,1986)$. Nestorov has observed clearly expressible quick polarization fading (that falls in the ULF range) of LF radio signal fluctuations hours and minutes prior to the Vrancea (Romania) M 7.9 EQ occurred at 19:22 UT on 4 March 1977. This quick fading has been recorded between 17:35 and 18:10 UT, i.e. it started approximately $2 \mathrm{~h}$ before the EQ shock. Of course, quick polarization fading of radio signals accompanies strong geomagnetic disturbances and statistically emerges in late evening and night hours under medium and high magnetic activity. Fortunately, the geomagnetic field activity around the EQ day, i.e. on 3-5 March 1977 was extremely low. Absorption records of other radio wave signals of higher frequency (LF and MF) diapason transmitted over the Vrancea area within the same time interval of several hours before the EQ shock at 19:22 UT have thus been analyzed. In fact, extremely quick fading of duration from $\sim 10$ up to $60 \mathrm{~min}$ at several radio frequencies $(164,182,209$, and $593 \mathrm{kHz})$ has been observed. The latter are recorded at different distances from the EQ epicentre. It proved that the observed fading recorded on different radio traces over the Vrancea EQ area is initiated at different times revealing in between variable time delay that increases with (radio trace) distance from the EQ.

This experimental fact has suggested an acoustic wave disturbance source concept testified by Nestorov (1986). He has compared the delay time and the distance between the LF radio reflection points (assuming that the disturbances are in the $\mathrm{D}$ and $\mathrm{E}$ regions) and the EQ hypocenter. By using error minimization method the acoustic wave-like disturbances source has been identified coinciding with the epicentre and the moment of its initiation has been evaluated to be approximately $2 \mathrm{~h}$ prior the main EQ shock.

The Nestorov's investigation (1986) is a pioneering observational evidence for EQ-related ionospheric variations propagating at acoustic velocity that precede strong EQ shock. The proposed explanation consists in generation of acoustic waves in the EQ hypocenter due to processes of friction that accompany and probably precede the main rupture moment.

Later, the acoustic gravity wave (AGW) and internal gravity wave (IGW) hypothesis has attracted more attention and basic mechanisms of AGW/IGW generation before strong EQ shocks have been suggested (Hegai et al., 1990; Mareev et al., 2002; Molchanov, 2004; Liperovsky et al., 2008). Recently, quasi 3-min fluctuations of vertical motion in the ionosphere have been detected 0-2 days prior to strong EQs (Liu et al., 2008). Hsiao et al. (2008) have examined wavelike structures and found that AGW can be activated near the epicenters, propagate into the ionosphere and then trigger traveling ionospheric disturbances (TIDs) few days before EQs traveling away from the EQ epicenter.

Existing studies and results thus suggest that pre-EQ effects in the ionosphere have significant signatures, of both day (1-7 days) and hour duration (minutes up to several hours) prior to EQ shock, at ionospheric heights typical of the F2, E, and D regions. Most of the effects are found to be distributed at large distances over the epicentral area. 
In our study, ionospheric disturbances during EQ activity in Central Italy in September and October 1997 are examined. Our attention is focused on ionospheric disturbances starting hours or minutes before the EQ shocks. A thorough examination of this problem can highlight both the mechanism of the lithosphere-atmosphere-ionosphere (L-A-I) interaction and the chain(s) of physical processes originating at the Earth crust and ending at the ionosphere.

\section{Earthquake activity in Central Italy during September-October 1997}

A long sequence of EQs, among them six with $M$ between 5 and 6 that struck Central Italy from September and December 1997 is thoroughly examined by Amato et al. (1998). The EQ series started of 3 September 1997 was followed by two strong shocks $\left(M_{\mathrm{w}} 5.7\right.$ at 00:33 UT, and $M_{\mathrm{L}} 6.4$ at 09:40 UT followed by another secondary EQ shock of $M_{\mathrm{L}} 5.3$ at 09:47 UT) on 26 September (according to NEIC catalogue), and it continued with four stronger shocks $\left(M_{\mathrm{w}}\right.$ between 5.3 and 5.7) occurred on 3, 6, 12, and 14 October 1997. $M_{\mathrm{L}}$ denotes the Richter magnitude scale, also known as the local magnitude $\left(M_{\mathrm{L}}\right)$ scale to quantify the amount of seismic energy released by an earthquake, while $M_{\mathrm{w}}$ characterizes the earthquake moment which is equal to the rigidity of the earth times the average amount of slip on the fault times the amount of fault area that slipped (see http://earthquake.usgs. gov/earthquakes/glossary.php $\{\#\}$ magnitude).

The shock events of 26 September, 3 and 6 October were located more northwardly than the ones of 12 and 14 October 1997, that occurred closer to Rome about $10-15 \mathrm{~km}$ southeast (Fig. 1). The EQ distribution delineated a NW-SE trending fault zone, elongated for about $40 \mathrm{~km}$, and extending for $5-15 \mathrm{~km}$ in the perpendicular direction.

The EQ shocks of 26 September 1997 were the strongest one (the first with $M_{\mathrm{w}}=5.7$ at 00:33 UT and the second with $M_{\mathrm{L}}=6.4$ at 09:40 UT). We study ionospheric variations on the EQ days using data recorded at the stations of Rome and Sofia. There are numerous investigations of the ionosphere dynamics at mid-latitudes and they have revealed that the ionospheric parameters correlate over appreciably greater distances in East-West than in North-South direction (Stanislawska et al., 1996a, b). The distance between Rome and Sofia (Rome and Sofia are nearly at the same latitude (of $\left.42^{\circ}\right)$ ) is $\sim 900 \mathrm{~km}$. Both ionosonde data, in terms of ionospheric parameters and ionograms, recorded at Sofia and Rome stations are thus considered to be compared. As it was pointed out, if there were EQ related disturbances, these variations would become most intense at hours just before the EQ shock.

In this paper we examine not only the ionospheric parameters changes, but the ionograms and all features visible on them. Ionospheric variations both at $\mathrm{E}$ and $\mathrm{F}$ region heights

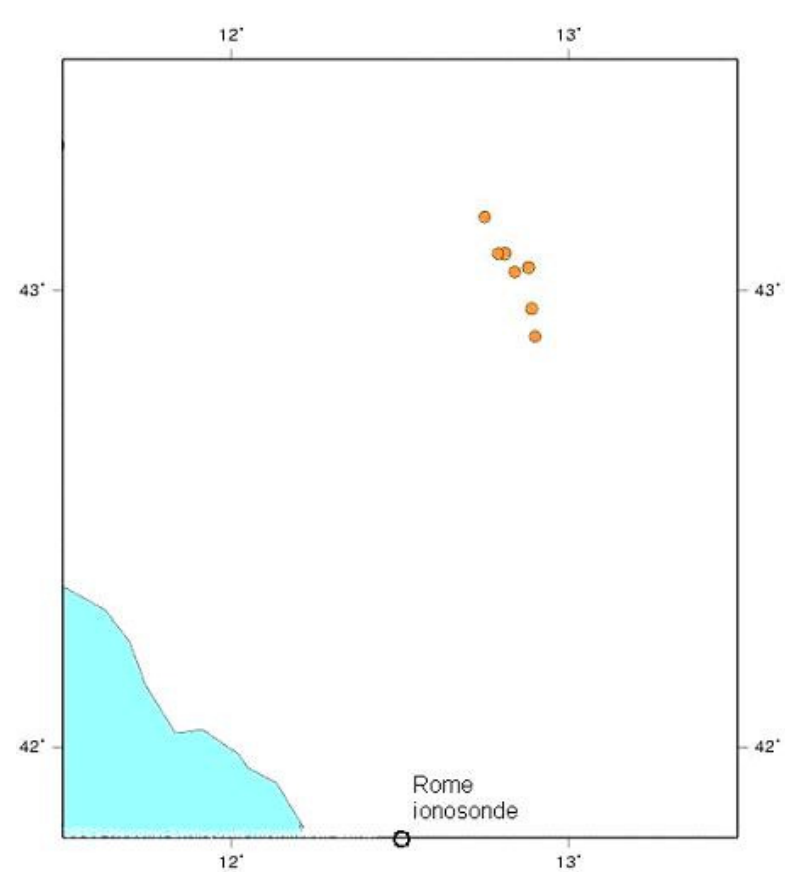

Fig. 1. Map of $M>5$ earthquakes occurred in Central Italy in September and October 1997.

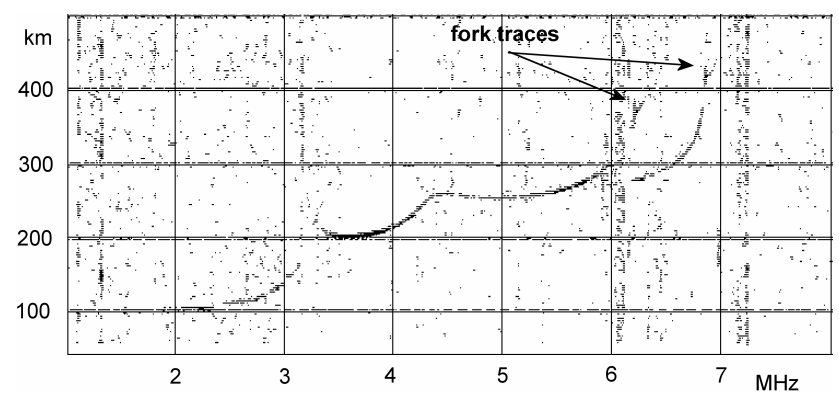

Fig. 2. Ionogram recorded on 26 September 1997 at Rome at 09:00 UT where fork traces, caused probably by TIDs, at critical frequencies of both the ordinary and extraordinary F2 rays are visible.

are considered. As it is expected, an initial inspection of the ionograms recorded in September and October 1997 reveals a similar behavior of the ionospheric plasma.

Ionograms from Rome and Sofia of 26 September 1997 do not reveal unusual features, they are practically of standard form (the geomagnetic activity on this day was low, Kp index was for several days less than 2). We notice that the first EQ shock on 26 September 1997 occurred at midnight hours (00:33 UT) and did not produce ionospheric disturbances in the $\mathrm{F} 2$ region (in night time $\mathrm{E}$ region is absent). The ionograms just before the second EQ shock (at 09:40 UT) are practically identical with one exception: an appearance in the Rome ionogram (Fig. 2) of "fork" on both traces corresponding to the ordinary and extraordinary mode of propagation. Figure 2 shows the ionogram recorded at 09:00 UT 


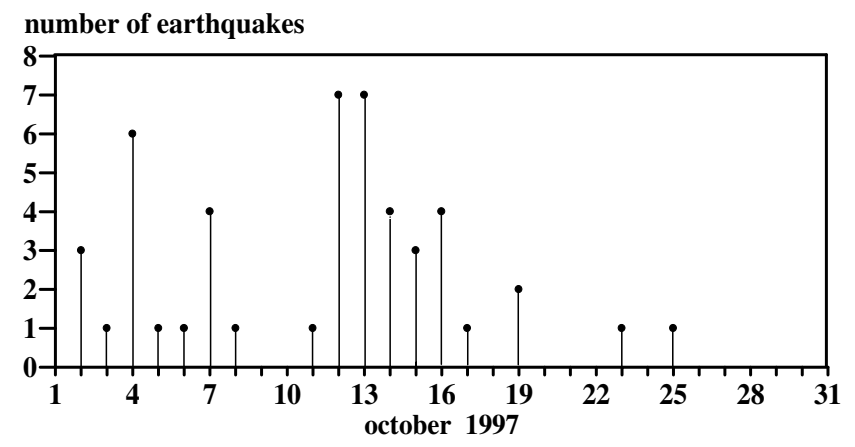

Fig. 3. Occurrence frequency of EQs with $M>4$ occurred in October 1997 at Central Italy.

$(\mathrm{LT}=\mathrm{UT}+1=10: 00)$. The fork that emerges at the critical frequencies of both F2 traces is closely connected with disturbances as TIDs (Hawlitschka, 2006). If the F2 fork is observed simultaneously on both traces as is our case, the TIDs propagate in north-south direction. Usually the F2 trace fork appearance is a nighttime phenomenon and hence, this case represents a peculiarity. Further, we shall see that similar forks are observed in daytime on another EQ day the 12 October 1997 (at 11:00 UT, i.e. at 12:00 LT).

Interesting disturbances at the $\mathrm{E}$ and intermediate $\mathrm{E}-\mathrm{F}$ region heights are observed on both 12 and 14 October 1997. The distance between the Rome station and the EQ epicenters on 12 and 14 October 1997 is $131-138 \mathrm{~km}$ and is shorter compared to EQs occurred on 26 September, 3, and 6 October 1997. Figure 3 illustrates the number of EQs occurred in October 1997, while Fig. 4 illustrates the EQ activity on 12, 13, and 14 October 1997. Inspecting the Rome ionograms on 12 October ionospheric disturbances are visible from one to two hours before the EQ shock. The EQ of $M=5.3$ on 12 October occurs at 11:08 UT. At 09:00, 10:00, 11:00, and 12:00 UT a sequence of transients characterizing the E-F region is observed in the ionograms recorded at Rome. At 09:00 UT a transient appears in the F1 region, where an F0.5 region is formed. Then, the disturbance interpreted as F0.5 region is observed at 10:00 and 11:00 UT. At 12:00 UT these structures are found at intermediate heights, between $\mathrm{E}$ and $\mathrm{F}$ regions (Fig. 5a, b, c, and d).

Similar features (in the intermediate E-F region) just before the EQ at 09:00, 10:00, and 11:00 UT are also observed at Sofia, as shown in Fig. 5e, and f.

The following features need to be mentioned:

- the E region parameters, as fmin (the lowest frequency of reflection recorded in the ionogram), foE (the critical frequency of the $\mathrm{E}$ region), and h'E (the minimum virtual height of the E layer) cannot be interpreted because of the absence of, or weak E region trace (E region stratification) (Fig. 5a. Both strong "non-deviative" absorption around the fmin and "deviative" absorption around foE take place at Rome. The trace disappears when a
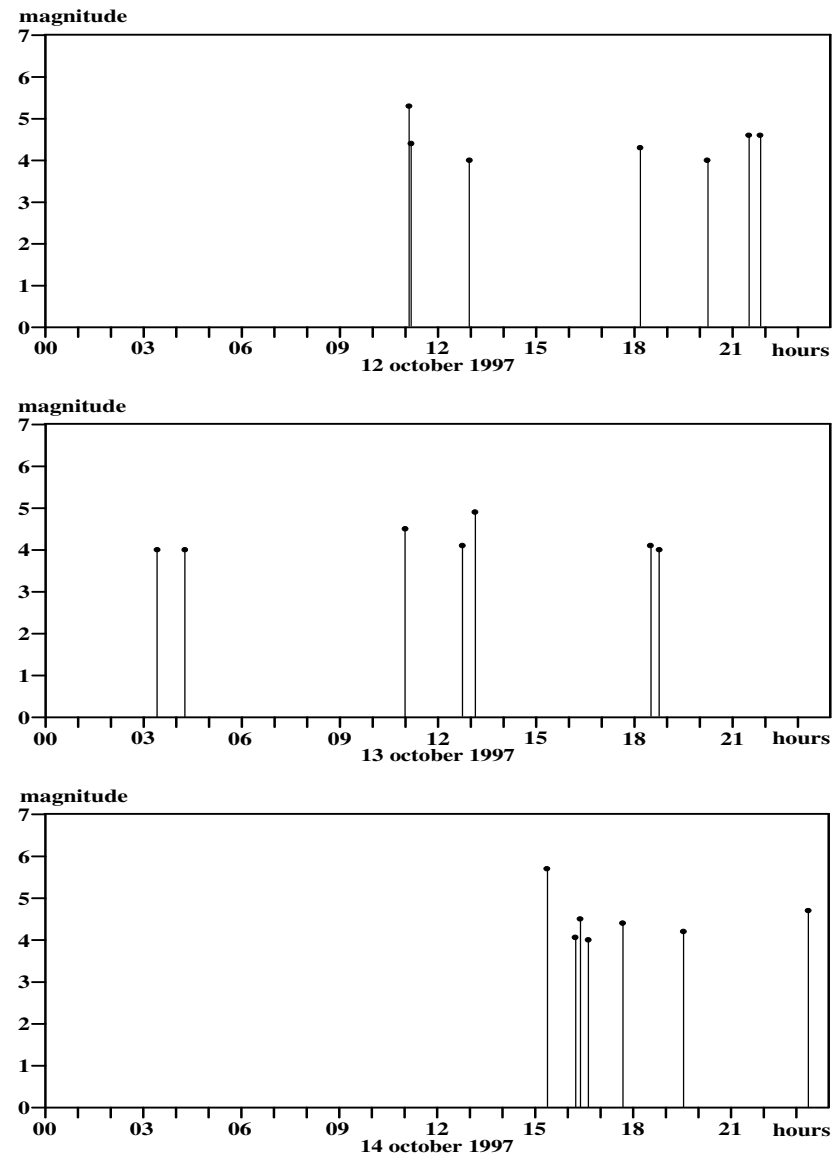

Fig. 4. EQ magnitude distribution on days 12, 13, and 14 October 1997. The strongest EQs occurred on 12 October at 11:08 UT, $(M=5.3)$ and on 14 October at 15:23 UT $(M=5.7)$.

change of the mechanism of reflection emerges, thus the normal strong reflected wave is replaced by an extremely weak reflection from the same height. This happens when a process of enhanced radio wave signal absorption emerges. The enhanced absorption effect usually is caused by an electron density increase in the D region through which the radio signal propagates. As we see from Fig. $5 \mathrm{c}$ the radio signal absorption extends at Rome continuously up to $2.9 \mathrm{MHz}$ and represents in this case the whole $\mathrm{E}$ region. The $\mathrm{E}$ region is thus not visible on the ionogram;

- at Rome an Es layer trace of short length, type c is observed. Its critical frequency is $3.1 \mathrm{MHz}$. At higher frequencies, a gap of $300 \mathrm{KHz}$ is visible. Within this gap a transients similar to high sporadic Es region is found (Fig. 5c). It might be a disturbance formed in the $\mathrm{F}$ region and descended in the heights of E-F region and transformed into a sporadic Es layer. There is however another possibility because the observed disturbances can be also interpreted as Es layer of type h; 

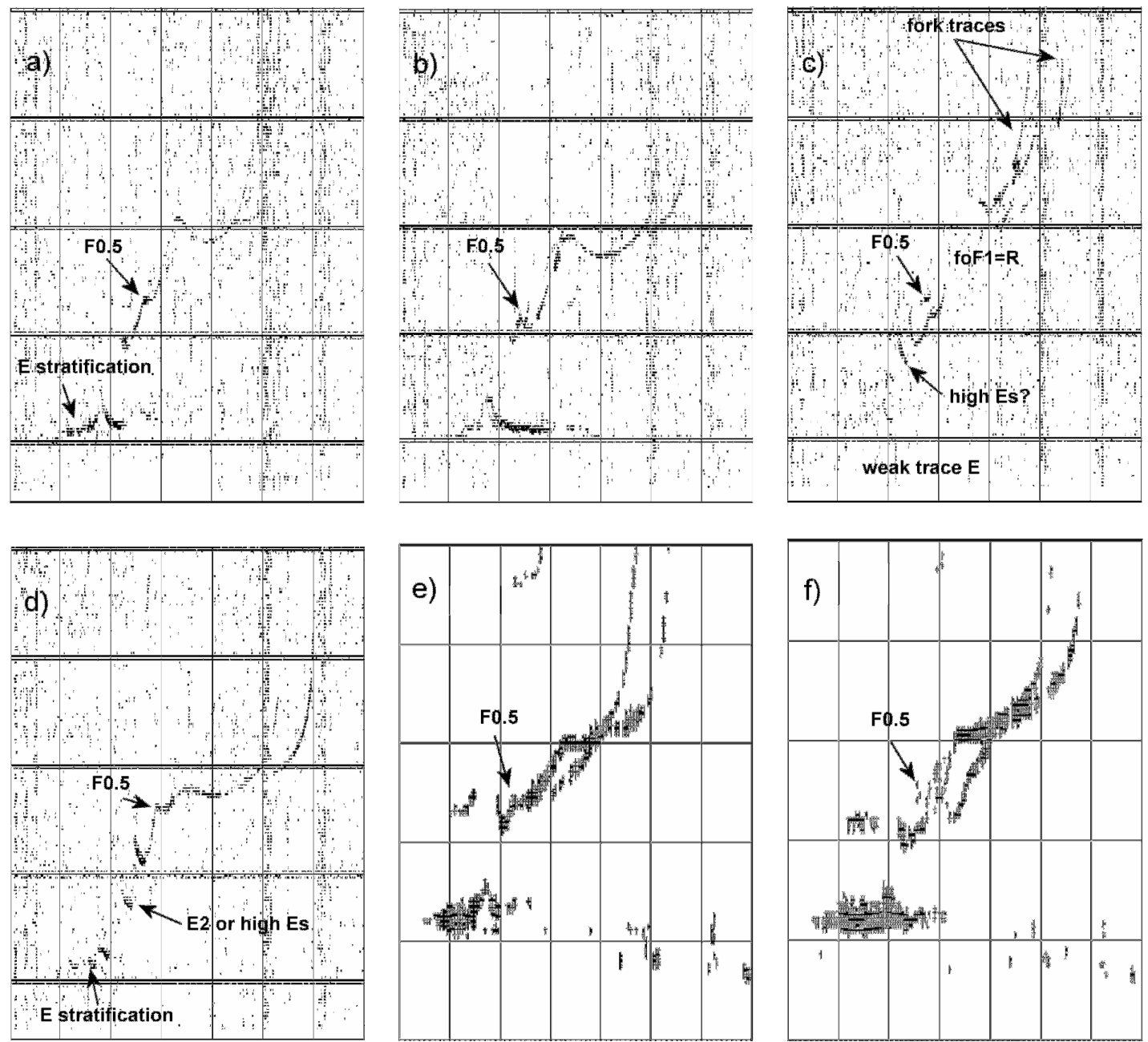

Fig. 5. Ionograms recorded on 12 October 1997 at Rome at (a) 09:00, (b) 10:00, (c) 11.00, and (d) 12:00 UT, and at Sofia at (e) 09:00, and (f) 11:00 UT. Grid lines are spaced $100 \mathrm{~km}$ vertically and $1 \mathrm{MHz}$ horizontally. At Rome, an F0.5 layer is visible in all the ionograms; at 11:00 UT, weak (practically absent) E region, Es layer of type h, and F2 fork traces are visible. At 12:00 UT (after the EQ shock) the E region appears with stratification, while high E2 or Es region persists. At Sofia, E region and F0.5 layer traces are well formed without effects of stratification and non-deviative and deviative absorption. The F2 fork traces observed at Rome are not visible at Sofia.

- the F1 region is without critical frequency (11:00 UT). It should be between 4.2 and $4.8 \mathrm{MHz}$. In this range the deviative absorption is strong, hence the critical frequency of the F1 region, foF1, is not visible ( $f \circ F 1=R$ ). The same consideration is valid for the corresponding lowest virtual height (h'F1=R);

- a splitting between $\mathrm{E}$ and $\mathrm{F} 1$ regions is observed at frequency foF0.5 =3.8 MHz;

- near the maximum frequency of reflection both the $\mathrm{O}$ and the $\mathrm{X}$ trace is characterized by a fork (Fig. $5 \mathrm{c}$ ). This, as it was previously said, suggests a TID-like transient that propagates along the north-south direction.
The Rome ionogram recorded the 12 October 1997 at 11:00 UT suggests that the ionosphere over Rome is strongly influenced by additional force(s) of unknown origin that act locally. These forces draw the ionosphere out of its normal large-scale condition. These features are of short time duration, they disappear after an hour. These transients are observed in the ionosphere over Rome and are not observed in the ionosphere above Sofia ionosonde station $(900 \mathrm{~km}$ from Rome). Indeed E region and F0.5 region traces are well formed at the two stations. Effects of stratification and nondeviative and deviative absorptions and F2 trace fork are observed at Rome. At the same time these effects are not visible at Sofia. 
Table 1. Ionospheric parameters on 12 October 1997 at 11:00 UT*.

\begin{tabular}{ccccccccccccc}
\hline & $\begin{array}{c}\text { fmin } \\
\mathrm{MHz}\end{array}$ & $\begin{array}{c}\text { foE } \\
\mathrm{MHz}\end{array}$ & $\begin{array}{c}\mathrm{h}^{\prime} \mathrm{E} \\
\mathrm{km}\end{array}$ & $\begin{array}{c}\text { foEs } \\
\mathrm{MHz}\end{array}$ & $\begin{array}{c}\text { h'Es } \\
\mathrm{km}\end{array}$ & $\begin{array}{c}\mathrm{fbEs} \\
\mathrm{MHz}\end{array}$ & $\begin{array}{c}\mathrm{Es} \\
\text { type }\end{array}$ & $\begin{array}{c}\text { foF0.5 } \\
\mathrm{MHz}\end{array}$ & $\begin{array}{c}\text { foF1 } \\
\mathrm{MHz}\end{array}$ & $\begin{array}{c}\text { h'F1 } \\
\mathrm{km}\end{array}$ & $\begin{array}{c}\text { foF2 } \\
\mathrm{MHz}\end{array}$ & $\begin{array}{c}\text { h'F2 } \\
\mathrm{km}\end{array}$ \\
\hline Rome & 2.2 & 2.9 & 108 & $\begin{array}{c}\mathrm{E} 2.9 \\
\mathrm{G}\end{array}$ & $\mathrm{G}$ & $\begin{array}{c}2.9 \\
\mathrm{G}\end{array}$ & - & 3.8 & 4.4 & 175 & 6.1 & $\begin{array}{c}\mathrm{U} 300 \\
\mathrm{R}\end{array}$ \\
Sofia & 1.7 & 3.0 & 110 & 4.3 & 115 & 3.2 & $\mathrm{c} 1$ & 3.8 & 4.3 & 195 & 6.2 & 300 \\
\hline
\end{tabular}

* At this time most of the parameters (foF1, foE, etc.) at Rome, as illustrated in Fig. 5, are not visible and consequently they are tentatively derived.

Table 2. Ionospheric parameters on 14 October 1997 at 07:00, 13:00, 13:45*, and 15:00 UT.

\begin{tabular}{|c|c|c|c|c|c|c|c|c|c|c|c|}
\hline hours & $\begin{array}{l}\text { fmin } \\
\mathrm{MHz}\end{array}$ & $\begin{array}{c}\text { foE } \\
\mathrm{MHz}\end{array}$ & $\begin{array}{l}\text { h'E } \\
\text { km }\end{array}$ & $\begin{array}{l}\text { foEs } \\
\mathrm{MHz}\end{array}$ & $\begin{array}{c}\text { h'Es } \\
\text { km }\end{array}$ & $\begin{array}{l}\text { fbEs } \\
\mathrm{MHz}\end{array}$ & $\begin{array}{l}\text { Es } \\
\text { type }\end{array}$ & $\begin{array}{c}\text { h'F1 } \\
\text { km }\end{array}$ & $\begin{array}{c}\text { h'F2 } \\
\text { km }\end{array}$ & $\begin{array}{l}\text { foF1 } \\
\mathrm{MHz}\end{array}$ & $\begin{array}{l}\text { foF2 } \\
\mathrm{MHz}\end{array}$ \\
\hline \multicolumn{12}{|c|}{ Rome } \\
\hline 07:00 & 1.8 & 2.4 & 115 & 2.6 & 160 & 2.6 & h1 & 230 & & & 6.4 \\
\hline $13: 00$ & 2.3 & 2.95 & 110 & 3.2 & 175 & 3.2 & h1 & 210 & 250 & $4.2 \mathrm{~L}$ & 6.6 \\
\hline & & & & & & & & & $\mathrm{L}$ & & \\
\hline $14: 00$ & 2.1 & 2.85 & 110 & 3.1 & 160 & 3.1 & h1 & 230 & 250 & $4.2 \mathrm{~L}$ & 7.2 \\
\hline $15: 00$ & 1.6 & 2.3 & 110 & 2.7 & 160 & 2.8 & h1 & 245 & $\mathrm{~L}$ & $\mathrm{~L}$ & 8.4 \\
\hline \multicolumn{12}{|c|}{ Sofia } \\
\hline 07:00 & 1.6 & 2.3 & 115 & 2.5 & 155 & 2.5 & h1 & 230 & & & 5.8 \\
\hline $13: 00$ & 1.7 & 2.95 & 105 & & & 3.0 & & 210 & & & 6.9 \\
\hline $13: 45$ & 1.6 & 2.85 & 110 & & & 2.8 & & 210 & 250 & 4.15 & 7.1 \\
\hline $15: 00$ & 1.6 & 2.0 & 120 & 2.6 & 145 & 1.9 & $\mathrm{c} 1$ & 245 & & & 7.4 \\
\hline
\end{tabular}

* The 13:45 UT ionogram at Sofia is taken into consideration instead of the 14:00 UT one because the latter is not available.

The main ionospheric parameters on 12 October 1997 are however coincident in both stations, as illustrated in Table 1. Let us outline them: i) the critical frequency foF2; ii) deflecting absorption around foF1 (in Sofia less than at Rome); iii) splitting evidence at the F1 heights (F0.5); iv) development of Es layer of type c (at Rome it is shorter and with gap), and v) the heights h'F1 and h'F2.

Similar features at the E-F region heights are also observed on 14 October 1997 during the $M_{\mathrm{L}} 5.7$ EQ occurred at 15:23 UT (see Fig. 6). It is remarkable that high Es layers of type h emerge at Rome hours before the EQ (see Fig. 6, panels a, b, c and d). After the EQ, the transients disappear and the ionosphere restores its normal conditions. Unlike Rome, at Sofia normal E region trace persists all time (see Fig. 6e and f) where Sofia ionograms at 13:00 and 14:00 UT only are depicted) and Es layers of type h do not appear. Table 2 summarizes all the $\mathrm{E}$ and $\mathrm{F}$ parameters measured at Rome and Sofia at 07:00, 13:00, 14:00, and 15:00 UT. The last $3 \mathrm{~h}$ are the closest to the EQ shock event. Note that white boxes indicate full coincidence of the values, green boxes indicate a coincidence within the interpretation errors, red boxes mark differences of about $20 \%$, and grey boxes denote differences greater than than $\pm 20 \%$. At 07:00 UT all the ionospheric parameters (except fmin and foF2) at Rome and Sofia are within the interpretation error. At 13:00 and 14:00 UT there are considerable differences in fmin $(2.3$ and $2.1 \mathrm{MHz}$ at Rome vs. 1.7 and $1.6 \mathrm{MHz}$ at Sofia); moreover at Rome the high Es layer and foEs are clearly observed and their parameters are well determined. At 15:00 UT the fbEs $(2.8 \mathrm{MHz})$ and the foE $(2.3 \mathrm{MHz})$ recorded at Rome are higher than the corresponding values $(1.9 \mathrm{MHz}$ and $2.0 \mathrm{MHz}$, respectively) recorded at Sofia. Estimated semi-transparency coefficient, $X=($ foEs-fbEs $) / \mathrm{fbEs}$, is somewhat different, according to different levels of small-scale turbulence characterizing Rome and Sofia. At 15:00 UT there are also Es layers, at Rome of type h, at Sofia of type c. At Rome Es layer of type h emerges earlier, at 13:00, and it continues at 14:00 UT.

The variations of the critical frequency of F2 region, i.e. foF2 variations have been the most exploited quantity among the ionospheric parameters examined as EQ precursors (Pulinets et al., 2003, 2004). We examine also the foF2 variations during September and October 1997, i.e. weeks and days before the main EQ shocks in Central Italy on 26 September, 3, 6, 12, and 14 October 1997 and also after 

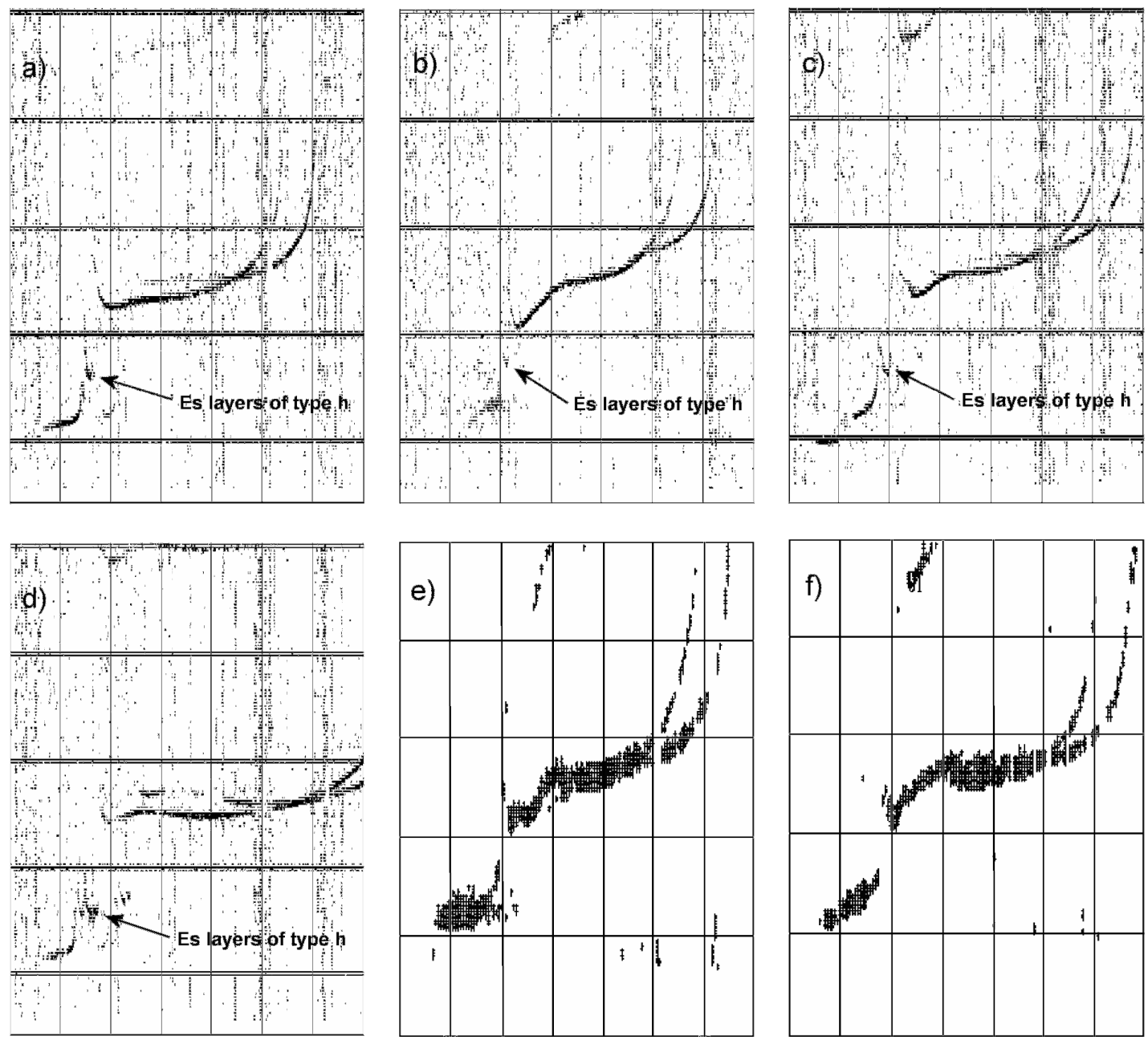

Fig. 6. Ionograms recorded on 14 October 1997 at Rome at (a) 07:00, (b) 13:00, (c) 14:00, and (d) 15:00 UT, and at Sofia at (e) 13:00, and (f) 14:00 UT. Grid lines are spaced $100 \mathrm{~km}$ vertically and $1 \mathrm{MHz}$ horizontally. At Rome Es layers of type h are visible in all the ionograms, strengthening at 15:00 UT; E region trace is almost absent at 13:00 UT. Unlike Rome, at Sofia the E region trace is well developed at 13:00 UT, and no Es layers of type $h$ are visible.

them. Figure 7 displays the foF 2 deviations from the corresponding monthly median values for September (Fig. 7a) and October 1997 (Fig. 7b), respectively. A comparison of foF2 deviations at Rome and Sofia stations reveals remarkable similar behavior of the foF 2 deviations. The foF 2 deviations at the two stations are highly correlative, decreases/increases of foF 2 deviations are practically unidirectional.

There are only two cases of exceptional decrease of the foF 2 parameter. These decreases however occur simultaneously at Rome and Sofia on 19 September (Fig. 7a) and on 11 October (Fig. 7b). The foF 2 deviation becomes $4.3 \mathrm{MHz}$ on 11 October 1997. Additionally a cross-correlation analysis for both ionospheric stations is carried out. The crosscorrelation coefficient is very high throughout and persists between 0.91 and 0.97 for all 6 days before the strongest EQ shock on 26 September 1997. The observed decrease of foF2 parameter on 19 September might be related to an enhanced geomagnetic activity, because, in this case it was preceded by a short time, but sizeable decrease of the Dst index. A careful examination shows that the foF2 decrease on 11 October can be interpreted as a signature of negative ionospheric storm at mid-latitudes (in our case after a sudden geomagnetic storm commencement occurred on 10 October 1997, Villante et al., 2001). It is well known that negative ionospheric storm phases are frequent phenomena in mid-latitude ionospheric regions. One should mention that the cross-correlation coefficient in October 1997 proves very variable, in a way that days of high cross-correlation coefficient are followed by days of decreased values of cross-correlation coefficients especially in the first half of October. For days before 14 October 1997 (the most strong earthquake shock in October) the cross-correlation coefficient has the following values: $0.67,0.23,-0.07,0.79,0.32$, and 0.58 . This fact might 

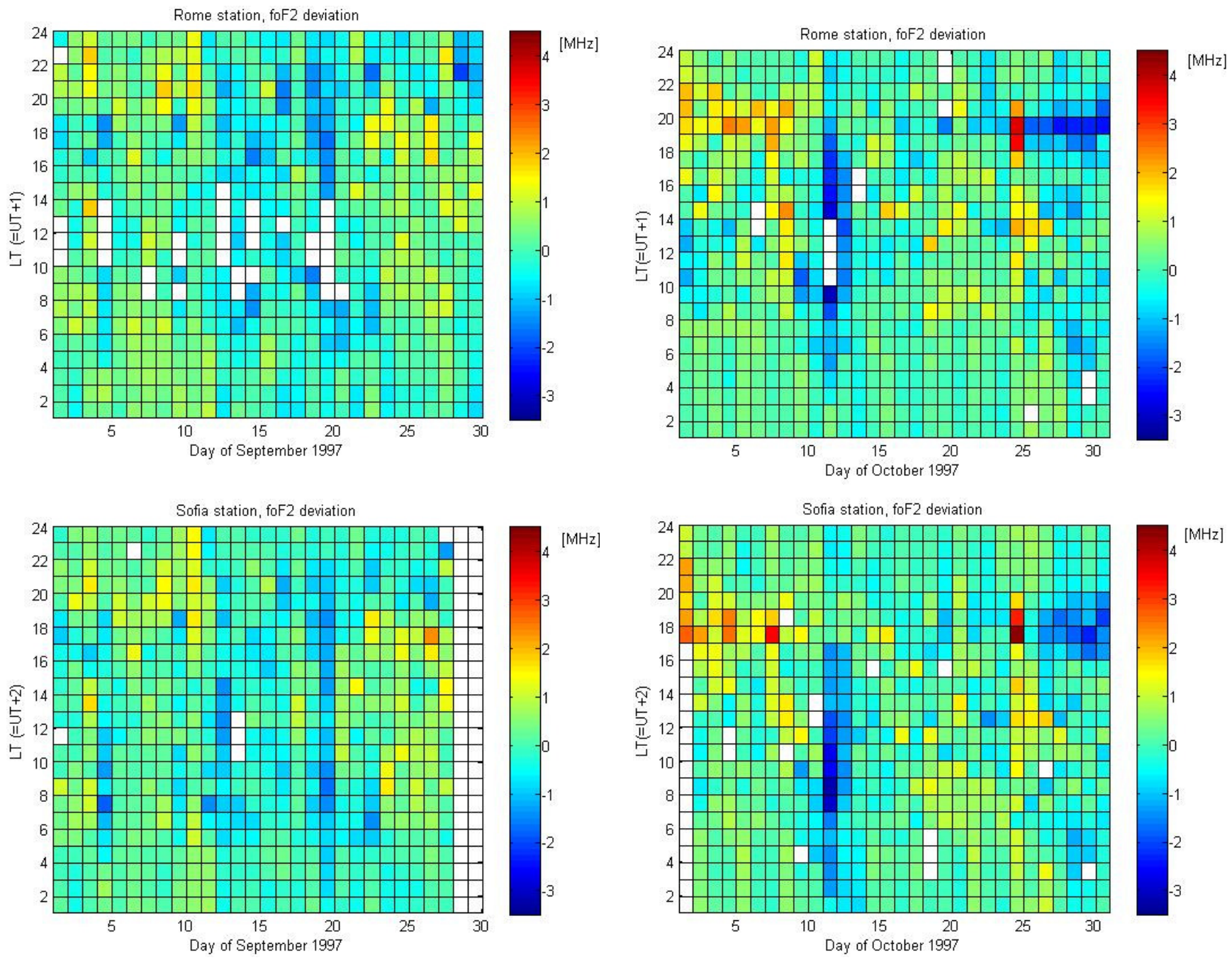

Fig. 7. The critical frequency (foF2) deviations from the corresponding monthly median values at Rome and Sofia ionospheric stations for September (a) and October 1997 (b) are depicted. Horizontal axis denotes days of month, vertical axis - local time (LT). The foF2 deviations are colored depending on the sign and magnitude for every day and LT. The white boxes spread indicate an absence of data for the foF2 parameter.

be explained with an enhanced variability of the geomagnetic activity in the first half of October (two sudden commencements, SCs, occur on 1 and 10 October 1997 where Kp index increases up to 6). On these SC days the cross-correlation coefficient reduces to 0.36 and 0.23 . The cross-correlation coefficient during the second part of October 1997 behaves stable ranging high values mostly within $0.7-0.8$.

An obvious absence of EQ-related foF2 parameter signature in Central Italy in 1997 might be explained in the light of latest findings, namely that foF2 deviations (either of negative or positive sign depending on the direction to the epicenter) associated with pre-EQ processes appear repeatedly only for seismic sources of depths greater than $60 \mathrm{~km}$ (Pulinets et al., 2004). The EQs in Central Italy occurred in 1997 are of shallow type (their depth is practically less than $10 \mathrm{~km}$ ).
One can suggest that effects traced by ionograms at Rome station on 12 and 14 October 1997 only are connected with: i) an enhanced radio wave dissipation of local origin (both of non-deviative and deviative type) resulting in considerable gaps in the ionospheric traces, and ii) generation of transients like Es layers of type $\mathrm{h}$ between $\mathrm{E}$ and $\mathrm{F}$ regions. On 12 and 14 October the $\mathrm{E}$ region traces at Sofia are clearly visible on ionograms, i.e. the non-deviative absorption above Sofia is thus not effective. Moreover, there is no Es layer of type $h$.

Hence, the differences in the ionogram traces recorded at Rome and Sofia on EQ days, 12 and 14 October 1997, are mainly localized in the $\mathrm{E}$ and $\mathrm{E}-\mathrm{F}$ regions.

At hours around the considered EQ shocks the geomagnetic activity was low, practically quiet, the geomagnetic index Kp varied between 1 and 2+. 
Table 3. Ionospheric transients prior to EQs with $M>5$. Distances between station and EQ epicenter are less than $200 \mathrm{~km}$ (Rome station, September-October 1997).

\begin{tabular}{|c|c|c|c|c|c|c|c|c|c|}
\hline Date & $\begin{array}{l}\text { Time } \\
\text { UT }\end{array}$ & Lat & Long & $\begin{array}{l}\mathrm{D} \\
\mathrm{km}\end{array}$ & $M$ & Es, type high & fmin change & $\begin{array}{c}\text { Non- and/or } \\
\text { deviative absorption }\end{array}$ & $\mathrm{F} 2$ trace fork \\
\hline \multirow[t]{3}{*}{26 Sep 1997} & $00: 33: 12$ & 43.05 & 12.88 & 146 & 5.7 & - & - & - & - \\
\hline & 09:40:26 & 43.08 & 12.81 & 148 & 6.4 & - & - & - & + \\
\hline & $09: 47: 38$ & 43.16 & 12.75 & 155 & 5.3 & - & - & - & + \\
\hline 3 Oct 1997 & $08: 55: 21$ & 43.08 & 12.79 & 147 & 5.3 & - & + & - & - \\
\hline 6 Oct 1997 & $23: 24: 52$ & 43.04 & 12.84 & 144 & 5.5 & $?$ & $?$ & $?$ & $?$ \\
\hline 12 Oct 1997 & 11:08:36 & 42.90 & 12.90 & 131 & 5.3 & + & + & + & + \\
\hline 14 Oct 1997 & $15: 23: 10$ & 42.96 & 12.89 & 138 & 5.7 & + & + & + & - \\
\hline
\end{tabular}

Table 4. Occurrence of sporadic Es layer, type h (Rome station, September-October 1997).

\begin{tabular}{|c|c|c|c|c|c|c|}
\hline $\begin{array}{l}\text { Time } \\
\text { LT }\end{array}$ & $\begin{array}{c}\text { h'Es }<130 \\
\text { km }\end{array}$ & $\begin{array}{c}130<\text { h'Es }^{\prime}<140 \\
\text { km }\end{array}$ & $\begin{array}{c}140<\text { h'Es }^{\prime}<150 \\
\text { km }\end{array}$ & $\begin{array}{c}150<\text { h'Es }^{\prime}<160 \\
\text { km }\end{array}$ & $\begin{array}{c}\text { h'Es }>160 \\
\mathrm{~km}\end{array}$ & all \\
\hline 07:00 & 2 & 4 & 3 & & 1 & 10 \\
\hline 08:00 & 5 & 5 & 1 & 4 & & 15 \\
\hline 09:00 & 1 & 5 & 1 & & & 7 \\
\hline 10:00 & 1 & 1 & & & & 2 \\
\hline 11:00 & & & & & & \\
\hline $12: 00$ & & & & & & \\
\hline $13: 00$ & & & & 1 & & 1 \\
\hline $14: 00$ & & & & & 1 & 1 \\
\hline $15: 00$ & & 2 & 2 & 1 & 2 & 7 \\
\hline $16: 00$ & 2 & 5 & 3 & 5 & & 15 \\
\hline $17: 00$ & 3 & 6 & & & & 9 \\
\hline
\end{tabular}

Table 3 summarizes transients observed prior to EQs of $M>5$ occurred in Central Italy in 1997. Sign - or sign + in the cells where they enter correspond to absence or presence of the relevant event (Es, fmin increase, non-deviative and/or deviative absorption, F2 trace fork). In Table 3 symbol '?' is used to indicate that ionograms data on this EQ day (6 October 1997) were not available. From this table, one concludes that transients like Es layers of type h, fmin increase, non-deviative and deviative absorptions, and F2 trace fork are frequently observed at Rome. At the same time, the Sofia ionosphere is close to its normal condition, or reveals large-scale variations which are simultaneously observable at Rome.

\section{Discussion}

The observed transients in the ionosphere demonstrate a different character of the low ionosphere dynamics locally. It is well known that local changes in the low ionosphere depend on several factors: meteorological, lithospheric, etc. The absence of E region traces for some time may imply a local source and energy release. Disturbances in the E region are suggestive for transient mechanism(s) working in the lower thermosphere/ionosphere. Transients as fmin increase and weak $E$ region trace, or E region stratification (with an enhanced trace gap around foE) can be explained with a short time (less than $15 \mathrm{~min}$ ) enhanced absorption of the radio wave sounding signal through the D and E regions. Sources of Es layers of type $\mathrm{h}$ are AGW, particle precipitations, neutral wind shears, etc.

In order to distinguish and discriminate ionospheric disturbances according to their genesis (meteorological, lithospheric, etc.), their spatial and temporal characteristics need to be established. Table 4 illustrates the occurrence frequency of sporadic Es layer (type h) distributed in day hours (07:00-17:00 LT) for September and October 1997. In the table the EQ days 12 and 14 October 1997 are excluded. According to the table, sporadic Es layer (type h) is frequently observed at morning (dawn) and afternoon (dusk) hours with two peaks of occurrence: at 07:00(08:00) LT and 16:00(17:00) LT and is excluded at 11:00 and 12:00 LT. Presumably, at given latitude the hours of Es (type h) occurrence 
peaks will move accordingly to sunrise and sunset moments depending on season. Hence, the sporadic Es layer type $h$ that emerges at noon hours on 12 October 1997, i.e. at 11:00 UT is an exception. Unfortunately, the sporadic Es layer observed on 14 October 1997 however cannot be discriminated from usual sporadic Es layers (type h) frequently occurred at 15:00-17:00 LT.

Another statistics is drawn about the fork events on F2 trace. For the two months period (1464 ionograms) there is only one fork event that occurred on 26 September 1997.

Our examination reveals ionospheric transients in the low ionosphere (at heights of the $\mathrm{E}$ and $\mathrm{E}-\mathrm{F}$ regions) and provides additional evidences for i) an increase of fmin, ii) emergence of Es layer, and iii) trace gaps around foE even $\mathrm{E}$ region trace disappearance that appear hours before the main EQ shocks. These local effects observed within $1 \mathrm{~h}$ even $2 \mathrm{~h}$ interval might be associated with pre-EQ related processes.

The main question that arises is: Can such different changes in the $\mathrm{E}$ region be recognizable as precursors of EQs? One should mention that ionospheric changes and disturbances during geomagnetically disturbed conditions are of large-scale characteristics as propagation, time and spatial scales. The latter can be easily monitored by an ionosonde network. In our study, within the time interval of several hours before the EQs the geomagnetic index $\mathrm{Kp}$ is low, i.e. the geomagnetic activity was low. This excludes a geomagnetic activity genesis of the $\mathrm{E}$ and $\mathrm{E}-\mathrm{F}$ region disturbances observed over Rome only. The observed ionospheric disturbances are of local, still unknown origin.

On the other hand, experimental observations of AGW and IGW in the atmosphere and ionosphere before strong EQs are scarce and not properly documented. With regard to this, the Nestorov's finding (1986) of acoustic wave-like disturbances as a cause of LF wave polarization fading being initiated two hours before the Vrancea EQ in 1977 has not attracted the right consideration. It is worth noting that Nestorov has suggested and testified successfully hypothesis that acoustic wave-like disturbances are a principal cause of ionospheric features in the $\mathrm{D}$ and $\mathrm{E}$ regions that result in short time quick polarization fading of LF and MF radio wave signals.

AGW/IGW effects on the ionosphere by itself are extensively studied. The well-known effect produced by AGW is a formation of Es layer when the velocity gradient in height exceeds a threshold value. Plasma density disturbances (being indicated by radio wave soundings) are expected to be developed in regions where the coupling between the neutral and ionized atmosphere is the strongest one, i.e. in the $\mathrm{D}$ and $E$ regions, i.e. it usually occurs at low ionosphere heights. Just before the EQ shock on 12 October 1997 a transient similar to Es layer of type $\mathrm{h}$ is generated in the ionosphere above Rome. Looking at Table 2 Es layers of type $\mathrm{h}$ repeatedly emerge at hours before the EQ shock on 14 October 1997 in the ionosphere above Rome. In the ionosphere above Sofia there is only one case of sporadic Es layer (at 15:00 UT) of type c. Propagation of AGW/IGW through the
$\mathrm{D}, \mathrm{E}$, and $\mathrm{F}$ regions might also explain the other observed effects: the E region stratification, the fmin increase, the nondeviative and deviative absorption, as well as the fork trace on foF 2 trace. These evidences would suggest AGW as a common source of the observed disturbances in the D and E ionospheric regions thus yielding an additional support of the AGW/IGW hypothesis of the L-A-I chain of processes which emerge hours prior to EQ shock. One of the most questioned mechanisms of the (L-A-I) coupling (Molchanov et al., 2004) is AGW generation near the Earth surface during the period just preceding the EQ and their penetration into the ionosphere. Each stage of this mechanism - AGW generation, AGW propagation through the atmosphere and AGW interaction with the ionospheric plasma - still needs clear physical explanation. One should hold in mind that the mechanisms of generation of ionospheric irregularities at heights between $\mathrm{E}$ and $\mathrm{F}$ regions and their features are different and thus their intensity and duration depend on the sources and their characteristics.

\section{Conclusions}

In this study we examine ionospheric variations during EQ activity with $M$ between 5 and 6 . The ionospheric variations are recorded at distances between 130 and $170 \mathrm{~km}$ away from the epicenters of EQs occurred in Central Italy. Consecutive ionograms from the Rome and Sofia ionospheric stations are compared and analyzed.

The following conclusions can be drawn from our analysis.

First, the ionospheric disturbances which are observed several hours before the EQ shocks can be classified into: i) an increase of fmin (non-deviative absorption), ii) a widening of gaps of "deviative" absorption near the critical frequencies of the $\mathrm{E}$ and $\mathrm{F} 1$ regions, and iii) a total or partial disappearance of $\mathrm{E}$ region trace on ionograms. In addition there are effects connected with the development of Es layers type h. The observed ionospheric transients last from ten minutes up to hours and have a different character. In most cases some of them appear, others do not appear.

Second, in most cases the observed effects (mainly in the low ionosphere) are of local character, i.e. they are of scales up to several hundred kilometers. In the absence of geomagnetic activity, their characteristics suggest a possible connection with AGW EQ-related genesis among several sources (e.g. meteorological, geographical, coastal), i.e. they might be associated with pre-EQ processes if others are excluded. Their diversity implies cumulative effects of forces acting simultaneously with the seismic-related one. The possible ionospheric effects due to different mechanisms thus need to be quantified properly.

The findings suggest that if EQ-related ionospheric transients were indeed produced they were surely superimposed on other ionospheric disturbances of various scales in time 
and size produced by other external forces on the ionosphere. This means that using one component of the L-A-I system, say, the ionosphere only, it is not possible to discriminate clearly seismic-related disturbances and/or signals even when they are of local character. Thus, simultaneous measurements/monitoring of all L-A-I components and processes (e.g. AGW and/or IGW) are required, e.g. gas and radon emission from the faults, electric and magnetic fields, thermal anomaly, air humidity, etc. In this context, the measurements of electric field variations, AGW as a probable agent of Es layer development and/or enhanced absorption (by LF and radio wave signal propagation) might be of use. We need more evidences of this type of disturbances in order to give a quantitative explanation of their mechanism production.

Acknowledgements. We thank the referees for their valuable comments and suggestions.

Edited by: M. E. Contadakis

Reviewed by: L. Alperovich and another anonymous referee

\section{References}

Amato, A., Azzara, R., Chiarabba, C., Cimini, G. B., Cocco, M., Di Bona, M., Margheriti, L., Mazza, S., Mele, F., Selvaggi, G., Basili, A., Boschi, E., Courboulex, F., Deschamps, A., Gaffet, S., Bittarelli, G., Chiaraluce, L., Piccinini, D., and Ripepe, M.: The 1997 Umbria-Marche, Italy, earthquake sequence: a first look at the main shocks and aftershocks, Geophys. Res. Lett., 25, 28612864, 1998.

Biagi, P. F., Piccolo, R., Ermini, A., Martellucci, S., Bellecci, C., Hayakawa, M., Capozzi, V., and Kingsley, S. P.: Possible earthquake precursors revealed by LF radio signals, Nat. Hazards Earth Syst. Sci., 1, 99-104, doi:10.5194/nhess-1-99-2001, 2001.

Chuo, Y. J., Liu, J. Y., Pulinets, S. A., and Chen, Y. I.: The ionospheric perturbations prior to the Chi-Chi and Chia Yi earthquakes, J. Geodyn., 33, 509-517, 2002.

Fraser-Smith, A. C., Bernardi, A., McGill, A. R., Ladd, M. E., Helliwell, R. A., and Villard, O. G.: Low frequency magnetic field measurements near the epicenter of the Ms 7.1 Loma-Pietra earthquake, Geophys. Res. Lett., 17, 1465-1468, 1990.

Gokhberg, M. B., Gulfeld, I. L., and Liperovsky, V. I.: Electromagnetic precursors in the earthquake system: search problem, Vestnik Acad. Nauk USSR, N3, 45-53, 1987.

Gokhberg, M. B., Gufeld, I. L, Rozhnoy, A. A., Marenko, V. F., Yampolsky, V. S., and Ponomarev, E. A.: Study of seismic influence on the ionosphere by super long wave probing of the Earthionosphere guide, Phys. Earth Planet. In., 57, 64-67, 1989.

Hawlitschka, S.: Travelling ionospheric disturbances (TIDs) and tides observed by a super-resolution HF direction finding system, J. Atmos. Sol.-Terr. Phy., 68, 568-577, 2006.

Hayakawa, M.: Atmospheric and Ionospheric Electromagnetic Phenomena Associated with Earthquakes, TERRAPUB, Tokyo, 1999.

Hayakawa, M. and Molchanov, O. A.: Seismo Electromagnetics Lithosphere-Atomosphere-Ionosphere Coupling, TERRAPUB, Tokyo, ISBN: 4-88704-130-6, 2002.
Hegai, H. H., Kim, V. P., and Nikiforova, L. I.: A possible generation mechanism of the acoustic gravity waves in the ionosphere before strong earthquakes, J. Earthquake Predict. Res., 6,. 584589, 1990.

Hsiao, C. C., Liu, J. Y., Oyama, K., Yen, N. L., Wang, Y. H., and Miaua, J. J.: Ionospheric electron density anomaly prior to the 26 December 2006 M7.0 Pingtung earthquake doublet observed by FORMOSAT-3/COSMIC, Phys. Chem. Earth, 34, 474-478, 2008

Liperovskaya, E. V., Pokhotelov, O. A., Hobara, Y., and Parrot, M.: Variability of sporadic E-layer semi transparency $\left(f_{o} E_{S^{-}}\right.$ $f_{b} E_{S}$ )with magnitude and distance from earthquake epicenters to vertical sounding stations, Nat. Hazards Earth Syst. Sci., 3, 279-284, doi:10.5194/nhess-3-279-2003, 2003.

Liperovsky, V. A., Pokhotelov, O. A., Liperovskaya, E. V., Parrot, M., Meister, C. V., and Alimov, O. A.: Modification Of Sporadic E-Layers Caused By Seismic Activity, Surv. Geophys., 21, 449486, 2000.

Liperovsky, V. A., Meister, C.-V., Liperovskaya, E. V., Vasil'eva, N. E., and Alimov, O.: On spread- $E_{S}$ effects in the ionosphere before earthquakes, Nat. Hazards Earth Syst. Sci., 5, 59-62, doi:10.5194/nhess-5-59-2005, 2005.

Liperovsky, V., Pokhotelov, O., Meister, C., and Liperovskaya, E.: Physical models of coupling in the lithosphere-atmosphereionopshere system before earthquakes, Geomagn. Aeronomy, 48, 795-806, 2008.

Liu, J. Y., Chen, Y. I., Chuo, Y. J., and Tsai, H. F.: Variations of ionospheric total electron content during the Chi-Chi earthquake, Geophys. Res. Lett., 28, 1383-1386, 2001.

Liu, J. Y., Chuo, Y. J., Shan, S. J., Tsai, Y. B., Chen, Y. I., Pulinets, S. A., and Yu, S. B.: Pre-earthquake ionospheric anomalies registered by continuous GPS TEC measurements, Ann. Geophys., 22, 1585-1593, 2004, http://www.ann-geophys.net/22/1585/2004/.

Liu, J. Y., Chen, Y. I., Chuo, Y. J., and Chen, C. S.: A statistical investigation of preearthquake ionospheric anomaly, J. Geophys Res., 111, A05304, doi:10.1029/2005JA011333, 2006.

Liu, J. Y., Chen, S. W., Chen, Y. C., Yen, H. Y., Chang, C. P., Chang, W. Y., Tsai, L. C., Chen, C. H., and Yang, W. H.: Seismoionospheric precursors of the 26 December 2006 M7.0 Pingtung earthquake doublet, Terr. Atmos. Ocean. Sci., 19, 751-759, 2008.

Mareev, E. A., Iudin, D. I., and Molchanov, O. A.: Mosaic source of internal gravity waves associated with seismic activity, in: Seimo-Electromagnetics (Lithosphere-AtmosphereIonosphere coupling), edited by: Hayakawa, M. and Molchanov, O., Terra Scientfic Publishing Company, Tokyo, 335-342, 2002.

Molchanov, O. A., Kopytenko, Y. A., Voronov, P. M., Kopytenko, E. A., Matiashvili, M. G., Fraser-Smith, A. C., and Bernardi, A.: Results of ULF magnetic field measurements near the epicenters of the Spitak (Ms =6.9) and Loma-Pietra (Ms=7.2) earthquakes: comparative analysis, Geophys. Res. Lett., 19, 1495-1498, 1992.

Molchanov, O. and Hayakawa, M.: Subionospheric VLF signals perturbations possibly related to earthquakes, J. Geophys. Res., 103(A8), 17489-17504, doi:10.1029/98JA00999, 1998.

Molchanov, O. A.: On the origin of low and middle latitude ionospheric turbulence, Phys. Chem. Earth, 59, 559-567, 2004.

Molchanov, O., Fedorov, E., Schekotov, A., Gordeev, E., Chebrov, V., Surkov, V., Rozhnoi, A., Andreevsky, S., Iudin, D., Yunga, 
S., Lutikov, A., Hayakawa, M., and Biagi, P. F.: Lithosphereatmosphere-ionosphere coupling as governing mechanism for preseismic short-term events in atmosphere and ionosphere, Nat. Hazards Earth Syst. Sci., 4, 757-767, doi:10.5194/nhess-4-7572004, 2004.

Nestorov, G. T.: A possible ionospheric presage of the Vrancha earthquake of March 4, 1977, Bolgarskaia Akademiia Nauk, Doklady (Comptes rendus de l'Academie bulgare des Sciences), 32(4), 443-446, 1979 (in English).

Nestorov, G.: Absorption and morphology of the lower ionosphere, Bulg. Acad. Sciences Publisher, Sofia, Chapter III, 136-141, 1986 (in Bulgarian).

Ondoh, T.: Anomalous Sporadic- $E$ Layers Observed before M 7.2 Hyogo-ken Nanbu Earthquake: Terrestrial Gas Emanation Model, Adv. Polar Upper Atmos. Res., 17, 96-108, 2003.

Ondoh, T. and Hayakawa, M.: Anomalous occurrence of sporadic E-layers before the Hyogoken-Nanbu earthquake, M 7.2 on January 17, 1995, in Atmospheric and ionospheric electromagnetic phenomena associated with earthquakes, edited by: Hayakawa, M., Tokyo, Terra Sci. Publ., 629-639, 1999.

Onwumechili, C. A.: A study of rocket measurements of ionospheric currents - II Ionospheric currents outside the dip equatorial zone, Geophys. J. Int., 108, 641-646, 1992.

Pulinets, S. A., Boyarchuk, K. A., Khegai, V. V., Kim, V. P., and Lomonosov, A. M.: Rocket observation of sporadic E layers and electron density irregularities over earthquake epicenters, Adv. Space Res., 26, 1209-1218, 2000.
Pulinets, S. A. and Boyarchuk, K. A.: Main Phenomenological Features of Ionospheric Precursors of Earthquakes, Chapter 5, in: Ionospheric precursors of earthquakes, Springer, 173-205, 2004.

Pulinets, S. A., Legen'ka, A. D., Gaivoronskaya, T. V., and Depuev, V. Kh.: Main phenomenological features of ionospheric precursos of strong earthquakes, J. Atmos. Sol.-Terr. Phy., 65, 13371347, 2003.

Pulinets, S. A., Liu, J. Y., and Safronova, I. A.: Interpretation of results of statistical analysis of critical frequency foF2 variations before earthquakes after Chung-Li ionospheric station data (Taiwan), Geomagn. Aeronomy, 44, 102-106, 2004 (Translated from Geomagnetizm i Aeronomiya, 44, 113-118, 2004).

Silina, A. S., Liperovskaya, E. V., Liperovsky, V. A., and Meister, C.-V.: Ionospheric phenomena before strong earthquakes, Nat. Hazards Earth Syst. Sci., 1, 113-118, doi:10.5194/nhess-1-1132001, 2001.

Stanislawska, I., Juchnikowski, G., and Gulyaeva, T. L.: Correlation distances based on ionospheric and geomagnetic catalogues, Proc. STPW, Hitachi, Japan, 387-390, January 23-27, 1996a.

Stanislawska, I., Juchnikowski, G., and Cander, L. R.: The Kriging method of ionospheric parameter f0F2 instantaneous mapping, Ann. Geofis., 34, 845-852, 1996 b.

Villante, U., Vellante, M., and Piancatelli, A.: Ultra low frequency magnetic field measurements during earthquake activity in Italy (September-October 1997), Ann. Geophys.-Italy, 44, 229-237, 2001. 